\title{
USE OF BLOOD DONORS WITH POSITIVE SEROLOGIC TESTS FOR SYPHILIS-WITH A NOTE ON THE DISAPPEARANCE OF PASSIVELY TRANSFERRED REAGIN
}

\author{
By MARK M. RAVITCH, THOMAS W. FARMER, AND BARBARA DAVIS \\ (From the Departments of Surgery and Medicine, The Johns Hopkins University and \\ Hospital, Baltimore)
}

(Received for publication June 9, 1948)

Transfusion syphilis is not a serious problem with present methods of blood transfusion. In The Johns Hopkins Hospital there were 12 recognized instances of transfusion syphilis before 1939 (1). Since the establishment of the blood bank in that year, no such cases originating in this hospital have been recognized. With serologically tested blood available at all times, transfusion syphilis is no longer caused by the use of untested blood in conditions of dire emergency.

Of equal importance is undoubtedly the effect of refrigerator storage. With the advent of mass transfusions $(6,000$ to 7,000 donors are bled each year in The Johns Hopkins Hospital blood bank), and the employment of nurse technicians to bleed the donors, physical examination of donors has become impractical. Obviously, some donors must have given blood at a time when they had lesions of primary syphilis. It is accepted that some 30 per cent of such individuals are seronegative. It is from just such donors that 25 per cent of the cases of transfusion syphilis originated in the past (2). It can hardly be mere chance that we have observed no cases of transfusion syphilis since 1939. Refrigerator storage must be the responsible factor. In 1941 Turner and Diseker (3) found that Treponema pallidum seeded in rabbit blood kept under conditions simulating those in the blood bank of The Johns Hopkins Hospital failed to give rise to infection when injected into rabbits after storage periods of 48 hours or longer. Bloch (4), simultaneously performing almost parallel experiments, found some persistence of infectivity up to 72 hours but none at 96 hours. Since most bank blood is three to four days old or older when used for blood transfusion and the experimental inoculations employed were much heavier than would be required to reproduce clinical conditions, it would appear that the absence of transfusion syphilis since the establishment of the blood bank is at least partly attributable to refrigerator storage.

The possible infectivity of plasma has also been studied. Kolmer (5) found inoculated liquid plasma infectious after one and three hours of storage at $4-6^{\circ} \mathrm{C}$. but not after 24,48 , or 72 hours. When serum inoculated with treponemes is frozen and desiccated, Turner, Bauer, and Kluth (6) found that under their experimental conditions infectivity of the spirochetes was completely destroyed. When inoculated plasma is frozen and held at $-20^{\circ} \mathrm{C}$. for 48 hours or longer, Ravitch and Chambers (7) found that the material is not infectious.

In civilian blood banks in areas where the incidence of syphilis in the population is high, as in Baltimore, large numbers of donors are rejected because of a history of syphilis or of antisyphilitic treatment. Other donors are bled but their blood discarded because of a positive serologic test for syphilis. ${ }^{1}$ In 1946, 1.2 per cent of white donors, 13.3 per cent of Negro donors, and 6.5 per cent of all donors-a total of 487 donors -at The Johns Hopkins Hospital, were found to have a positive STS and their blood discarded.

The evidence given above appears to be suffcient to indicate that with the use of plasma in any form (since it is necessarily held for bacteriologic culture for one week before release) there is no danger of transfusion syphilis. The importance of this in a military emergency is obvious. As far as concerns the danger of transmission of syphilis, no STS need be performed and no donor need be rejected in any plasma program. There remains only the problem of whether the passive transfer of reagin produces a positive STS in the recipient. To clarify this phase of the problem, plasma of known reagin titer was injected into individuals with a negative STS.

\footnotetext{
1 Hereafter this is abbreviated to STS.
} 
Less direct studies of the fate of passively acquired reagin of syphilis have been made by Fildes (8), Cruickshank (9), Dunham (10), and others (11). They observed that reagin was often passively transferred from the blood stream of women with positive STS to the circulation of their new-born infants. The majority of such infants, although not infected with Treponema pallidum, had positive STS at birth. Repeated quantitative STS in these infants showed a definite decline in the titer within seven days. The reactions were usually negative within 30 days, although in an occasional infant the passively transferred antibody could be detected for as long as 90 days. These observations represent passive transfer occurring in nature, analogous to the artificial transfusion of reagin-containing plasma into individuals with a negative STS. Recent studies by the technique of introduction of isotopic nitrogen into antibodies against type-specific pneumococci (12) show that the half-life of such an antibody molecule is approximately two weeks. There is no evidence of continued synthesis of passively transferred antibody.

\section{METHOD}

The subjects were all patients on the surgical service of The Johns Hopkins Hospital. At first only patients with known malignant disease were used, but as the results began to show the rapid return of the STS to negative, other types of patients were included. Sixteen patients with negative STS were studied.

All bottles of blood from donors with a positive STS were put aside in the refrigerator. As they accumulated, the plasma was drawn off and pooled, eight to ten donors contributing to each pool. The period of storage before centrifugation of blood and separation of plasma varied from one to ten days. The STS was titered for each unit of plasma entering the pool and for each pool. The plasma pools were at once divided into units of $500 \mathrm{cc}$. and then frozen at $-10^{\circ}$ to $-20^{\circ} \mathrm{C}$. At intervals of two weeks to two months the frozen plasma was thawed in a water bath at $37^{\circ} \mathrm{C}$. and $500 \mathrm{cc}$. administered intravenously to selected patients. The titer of the STS of each plasma unit after thawing was identical with the original titer. Specimens of blood were drawn from each recipient immediately before the plasma injection and at 24-hour intervals thereafter until the STS by all methods had become negative. In a few recipients several blood samples were taken during the first 24 hours.

Standard quantitative serologic tests were performed with the Mazzini technique (13), the Eagle flocculation (13), the Venereal Disease Research Laboratory Cardiolipin flocculation (14), and the Eagle Wassermann tech-

TABLE I

Serologic response in 16 patients with negative serologic tests for syphilis given $500 \mathrm{ml}$. of plasma with positive serologic tests for syphilis

\begin{tabular}{|c|c|c|c|c|c|c|c|c|c|c|c|}
\hline \multirow{4}{*}{ No. } & \multirow{4}{*}{ ient } & \multicolumn{5}{|c|}{ Plasma injected } & \multicolumn{4}{|c|}{$\begin{array}{l}\text { Serologic titers in patients } 24 \text { hours } \\
\text { after injection of plasma }\end{array}$} & \multirow{4}{*}{$\begin{array}{l}\text { Day after } \\
\text { injection } \\
\text { on which } \\
\text { all serol. } \\
\text { tests were } \\
\text { negative }\end{array}$} \\
\hline & & \multirow{3}{*}{ Lot No. } & \multicolumn{4}{|c|}{ Serologic titers } & \multirow{3}{*}{$\begin{array}{c}\begin{array}{c}\text { Comple- } \\
\text { ment } \\
\text { fixation }\end{array} \\
\text { Eagle }\end{array}$} & \multirow{2}{*}{\multicolumn{3}{|c|}{ Flocculation }} & \\
\hline & & & ment & \multicolumn{3}{|c|}{ Flocculation } & & & & & \\
\hline & & & Eagle & Eagle & Mazzini & Cardiolipin & & Eagle & Mazzini & Cardiolipin & \\
\hline $\begin{array}{r}1 \\
2 \\
3 \\
4 \\
5 \\
6 \\
7 \\
8 \\
9 \\
10 \\
11 \\
12 \\
13 \\
14 \\
15 \\
16\end{array}$ & $\begin{array}{r}\boldsymbol{k g} . \\
55 \\
66 \\
82 \\
39 \\
55 \\
64 \\
65 \\
42 \\
54 \\
65 \\
68 \\
59 \\
104 \\
80 \\
46 \\
60\end{array}$ & $\begin{array}{r}2 \\
2 \\
2 \\
4 \\
4 \\
4 \\
4 \\
8 \\
8 \\
8 \\
8 \\
9 \\
9 \\
10 \\
10 \\
10\end{array}$ & $\begin{array}{l}32 \\
32 \\
96\end{array}$ & $\begin{array}{l}16 \\
32 \\
64\end{array}$ & $\begin{array}{l}16 \\
32 \\
64\end{array}$ & $\begin{array}{r}32 \\
64 \\
128\end{array}$ & $\begin{array}{r}4 \\
1 \\
D \\
D \\
D \\
D \\
D \\
D \\
D \\
D \\
D \\
D \\
2 \\
D \\
4 \\
12 \\
4\end{array}$ & $\begin{array}{c}1 \\
D^{*} \\
1 \\
D \\
1 \\
D \\
1 \\
1 \\
1 \\
1 \\
2 \\
D \\
D \\
2 \\
8 \\
16 \\
16\end{array}$ & $\begin{array}{l}1 \\
\text { D } \\
\text { D } \\
\text { D } \\
\text { D } \\
\text { D } \\
1 \\
- \\
- \\
- \\
- \\
- \\
- \\
32\end{array}$ & $\begin{array}{r}2 \\
1 \\
\text { D } \\
1 \\
2 \\
1 \\
2 \\
1 \\
1 \\
2 \\
2 \\
2 \\
4 \\
16 \\
32 \\
32\end{array}$ & $\begin{array}{r}12 \\
10 \\
6 \\
4 \\
19 \\
19 \\
9 \\
14 \\
20 \\
5 \\
5 \\
12 \\
9 \\
8 \\
19 \\
10\end{array}$ \\
\hline
\end{tabular}

$* \mathrm{D}=$ doubtful. 
nique (13). Sera were examined within 24 hours after they were drawn. In addition a portion of each serum was frozen at $-10^{\circ} \mathrm{C}$. In this way all of the specimens drawn from a given patient could subsequently be tested simultaneously after the last specimen had been drawn. Since the results obtained on retesting were practically identical with the original determinations, the results reported here are those obtained with fresh sera. The methods of reporting used by the respective authors of the tests were followed in determining the titers.

\section{RESULTS}

1. Serologic titers of plasma pools. The serologic titers of the five pools of plasma used in these studies are presented in Table I. In the preparation of pools No. 2 and No. 4 any plasma was used if the corresponding serum had a titer of 1 dilution unit or higher with the Eagle flocculation test. In the pooling of Nos. 8, 9, and 10, plasma was taken only from donors with a titer of 4 dilution units or higher with the Eagle flocculation test. As a result of this the serologic titers in these latter pools were higher. The titers of the pools of plasma varied from 4 to 128 dilution units with the various tests employed.

2. Serologic titers in sera of recipients within the first 24 hours after the plasma infusion. Blood specimens drawn from each of the 16 recipients within the first 24 hours after infusion gave positive or doubtful reactions in all cases. The indi-

TABLE II

Duration of positive serologic test for syphilis after injection-comparison of the several serologic tests

\begin{tabular}{|c|c|c|c|c|c|}
\hline \multirow{3}{*}{$\begin{array}{l}\text { Patient } \\
\text { No. }\end{array}$} & \multicolumn{5}{|c|}{ Day after injection on which STS became negative } \\
\hline & \multirow{2}{*}{$\begin{array}{c}\begin{array}{c}\text { Comple- } \\
\text { ment } \\
\text { fixation }\end{array} \\
\text { Eagle }\end{array}$} & \multicolumn{3}{|c|}{ Flocculation } & \multirow{2}{*}{ All tests } \\
\hline & & Eagle & Mazzini & Cardiolipin & \\
\hline $\begin{array}{r}1 \\
2 \\
3 \\
4 \\
5 \\
6 \\
7 \\
8 \\
9 \\
10 \\
11 \\
12 \\
13 \\
14 \\
15 \\
16\end{array}$ & $\begin{array}{r}5 \\
4 \\
4 \\
2 \\
3 \\
5 \\
5 \\
14 \\
12 \\
2 \\
2 \\
2 \\
2 \\
5 \\
13 \\
10\end{array}$ & $\begin{array}{r}7 \\
4 \\
4 \\
2 \\
8 \\
5 \\
9 \\
3 \\
15 \\
5 \\
5 \\
12 \\
9 \\
9 \\
19 \\
10\end{array}$ & $\begin{array}{l}8 \\
4 \\
3 \\
2 \\
3 \\
2 \\
5 \\
- \\
- \\
- \\
\\
- \\
\\
9 \\
7\end{array}$ & $\begin{array}{r}12 \\
10 \\
6 \\
4 \\
19 \\
19 \\
9 \\
4 \\
20 \\
5 \\
5 \\
12 \\
9 \\
8 \\
16 \\
10\end{array}$ & $\begin{array}{r}12 \\
10 \\
6 \\
4 \\
19 \\
19 \\
9 \\
14 \\
20 \\
5 \\
5 \\
12 \\
9 \\
8 \\
19 \\
10\end{array}$ \\
\hline
\end{tabular}

vidual serologic titers varied from 1 to 32 dilution units in the various tests used (Table I).

3. Progressive fall in serologic titer in relation to time. In each case studied the quantitative serologic tests for syphilis gave the maximal response on the first day after infusion. On successive days after transfusion the serologic titers gradually fell in all cases until all serologic tests became negative. There was a rapid fall in titer within the first seven days. Fifteen of the 16 patients had serologic titers of 1 dilution unit or less on the seventh day. The sera of all the recipients became negative within nine to 19 days after injection, with minor fluctuations between tests (Table II). The fall in serologic titer of two of these patients is illustrated in Figures 1 and $2 .^{2}$

4. Later serologic follow-up of patients. None of the patients developed clinical evidence of transfusion syphilis and all of those who could be followed for three to six months maintained their negative STS. Of the 16 patients to whom plasma was given, ten returned for examinations three to six months later and were found to have negative STS at that time. Four of the group had died of their original neoplastic processes, and two could not be found for follow-up examinations.

In reviewing the records of these patients it was found that all of them received penicillin at the time of their surgical procedures. The total dosages of penicillin ranged from $10,000,000$ to $50,000,000$ Oxford units over periods of seven to 20 days. So that, inadvertently, these patients received adequate treatment for incubating primary syphilis (15). Since under present clinical practice the vast majority of patients sick enough to require transfusions also receive penicillin, the

2 While this study was in progress we had the opportunity to observe the effect of a transfusion of STS positive whole blood, erroneously administered. The donor's STS was positive in a titer of 16 dilution units (Eagle). The donor's blood had been stored for ten days at $5^{\circ} \mathrm{C}$. The recipient had a negative STS on admission to the hospital. She was a pregnant woman, at term, transfused for secondary anemia. Six days after the transfusion with $500 \mathrm{cc}$. of STS positive blood her STS was positive (Eagle 2 units, VDRL Cardiolipin 4 units). Nine days after the transfusion all serologic tests were negative. Two days after the transfusion the patient was delivered of a normal infant. The baby's STS was negative when first determined on the ninth day of life. 


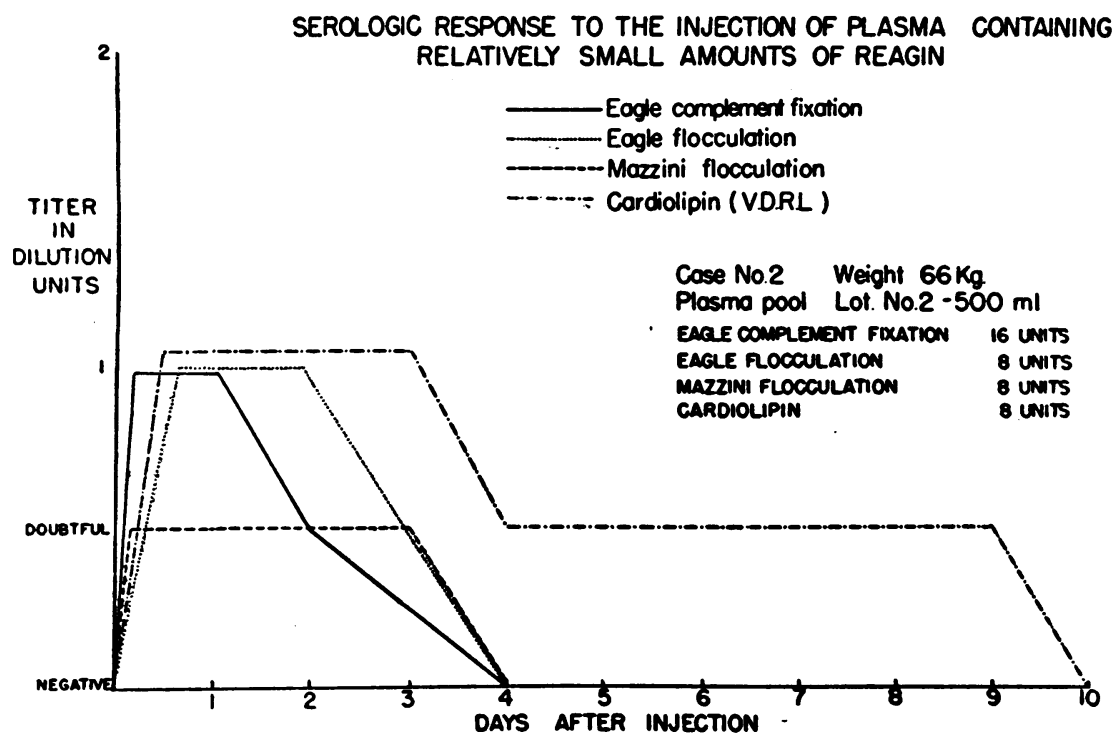

Fig. 1. After Injection of 500 cc. of Plasma of Low Titer STS, the Recipient's Immediate STS Is Positive in Low Titer, and at Ten Days the STS Is Negative by All Tests

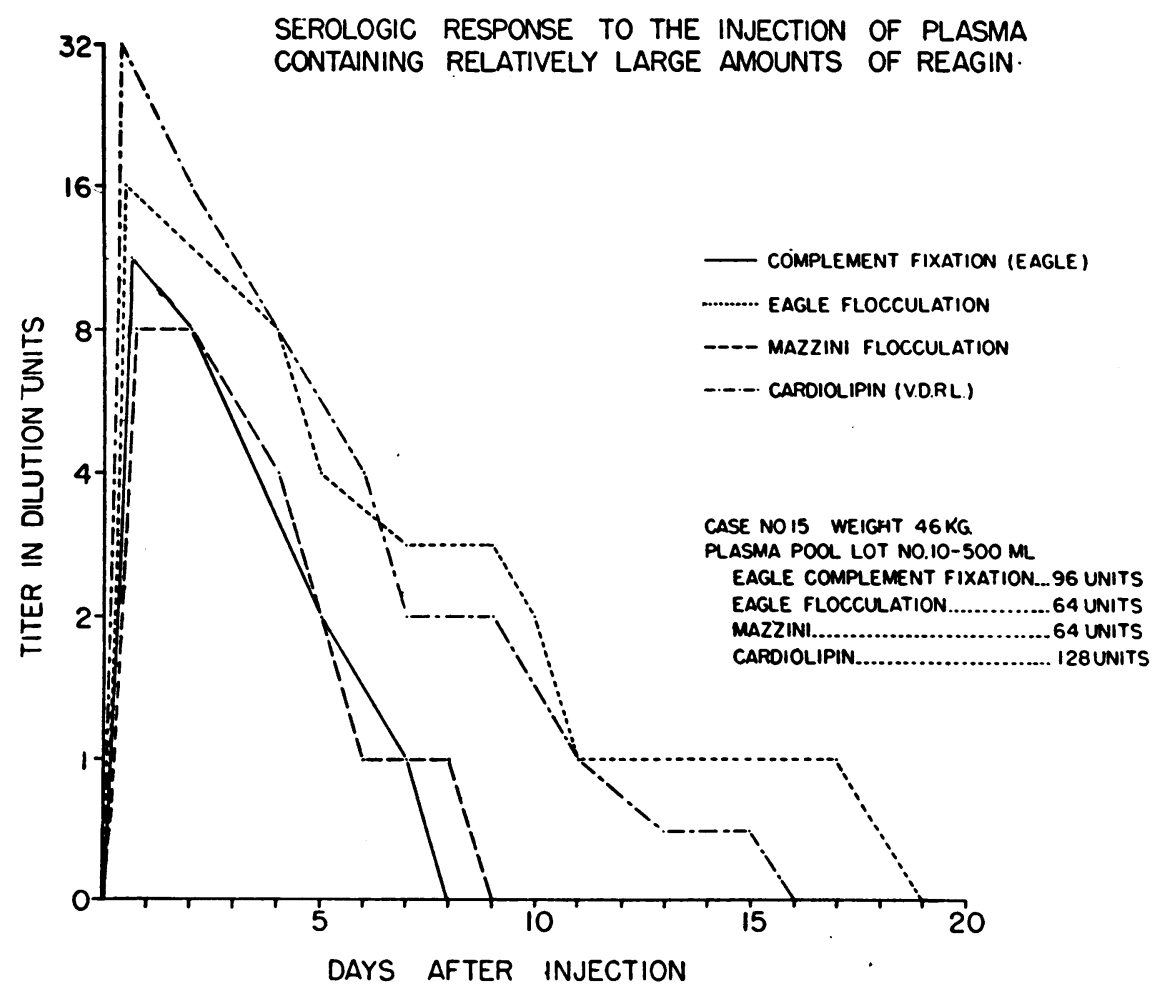

Fig. 2. After Injection of 500 cc. of Plasma of High Titer StS, the REcipient's Immediate STS Is Positive in High Titer, and It Requires 19 Days for the STS to Return to Negative by All Tests 
likelihood of the occurrence of transfusion syphilis is even further diminished.

\section{DISCUSSION}

The weights of the patients varied from 39 to $104 \mathrm{~kg}$. (Table I). If one uses the figure of 45 cc. of plasma volume per kilogram of body weight (16), then the computed plasma volumes for these 16 patients ranged from 1,755 to 4,680 cc. To these initial volumes there was added 500 cc. of plasma containing reagin. It can be calculated that the antibody was diluted in vivo approximately one-fifth to one-tenth of its original titer. In the actual tests of the recipients' sera on the day following injection it was observed that one-fourth to $1 / 32$ of the original titer was found in the recipients' sera. It would appear, within the range of error involved in the computation and in the titration of the sera, that the antibody titer of the recipient after 24 hours represented the dilution of the injected reagin in the blood volume of the recipient.

All of the plasma used in this study was taken from blood of donors known to have a positive STS and preferably of high titer. Yet, even under these extreme experimental conditions, the positive STS in the recipient lasted less than three weeks in the longest instance and only four days in the shortest. If the STS positive blood normally discarded by the blood bank were converted to plasma together with all the STS negative blood usually processed into plasma, no pool would have more than one or two STS positive specimens in it. The resultant pool of plasma would have a very low titer of reagin and the duration of the persistence of the passively transferred positive STS, if any were detectable at all, would be correspondingly brief. In all probability no more than a doubtful reaction would be produced in the recipient.

It is experimentally proved that syphilis will not be transmitted by plasma desiccated or frozen under blood bank conditions. Liquid plasma stored at $4-6^{\circ} \mathrm{C}$. one day or more is equally safe. We have now shown that the positive STS passively acquired by the recipient of a transfusion with STS positive plasma is of short duration. The blood of donors with syphilis in any stage should, therefore, be acceptable for use in the plasma program of any institution or organiza- tion, in which plasma is desiccated, frozen, or refrigerated under the conditions noted above.

\section{SUMMARY}

1. Patients transfused with plasma from donors with a positive serologic test for syphilis will acquire a positive STS.

2. The initial titer of the acquired STS represents the dilution in the recipient's blood volume of the reagin contained in the injected plasma.

3 . In all of 16 recipients the acquired positive STS had reverted to negative by the 20 th day or before.

4. The blood of donors with syphilis should be acceptable for use in any blood bank with a plasma program, provided the material has been frozen, dried from the frozen state, or stored at least four days in the refrigerator.

\section{BIBLIOGRAPHY}

1. Cantrell, J. R., and Ravitch, M. M., Transmission of disease by transfusion of blood and plasma. Am. J. Med. To be published.

2. Eichenlaub, F. J., and Stolar, R., Syphilis acquired from transfusion and its control. Pennsylvania Med. J., 1939, 42, 1437.

3. Turner, T. B., and Diseker, T. H., Duration of infectivity of Treponema pallidum in citrated blood stored under conditions obtaining in blood banks. Bull. Johns Hopkins Hosp., 1941, 68, 269.

4. Bloch, O., Jr., Loss of virulence of Treponema pallidum in citrated blood at $5^{\circ} \mathrm{C}$. Bull. Johns Hopkins Hosp., 1941, 68, 412.

5. Kolmer, J. A., A note on the survival of Treponema pallidum in preserved citrated human blood and plasma. J. Syph., Gonorr., \& Vener. Dis., 1942, 26, 156.

6. Turner, T. B., Bauer, J. H., and Kluth, F. C., The viability of the spirochetes of syphilis and yaws in desiccated blood serum. Am. J. Med. Sc., 1941, 202, 416.

7. Ravitch, M. M., and Chambers, J. W., Spirochetal survival in frozen plasma. Bull. Johns Hopkins Hosp., 1942, 71, 299.

8. Fildes, P., The prevalence of congenital syphilis amongst the newly born of East End of London. J. Obst. \& Gynec., 1915, 27, 124.

9. Cruickshank, J. N., Child Life Investigations. Maternal Syphilis as a Cause of Death of the Foetus and of the New Born Child. A Study of Congenital Syphilis Based on Serological, Clinical, and Post-Mortem Findings. Medical Research Council, Special Report Series No. 82. London, His Majesty's Stationery Office, 1924, p. 20.

10. Dunham, E. C., The diagnosis of congenital syphilis in the new-born. Am. J. Dis. Child., 1932, 43, 317. 
11. Roby, J., and Lembcke, P. A., Meaning and reliability of umbilical cord Wassermann tests. Am. J. Syph., 1933, 17, 473.

Faber, H. K., and Black, W. C., Quantitative Wassermann tests in diagnosis of congenital syphilis; clinical importance of Fildes' law. Am. J. Dis. Child., 1936, 51, 1257.

Christie, A. U., Diagnosis of syphilis in new-born infants. Use of quantitative Wassermann tests. Am. J. Dis. Child., 1938, 55, 979.

Goodwin, M. S., and Moore, J. E., Penicillin in the prevention of prenatal syphilis. J. A. M. A., 1946, $130,688$.

12. Schoenheimer, R., Ratner, S., Rittenberg, D., and Heidelberger, M., The interaction of antibody protein with dietary nitrogen in actively immunized animals. J. Biol. Chem., 1942, 144, 545.

Heidelberger, M., Treffers, H. P., Schoenheimer, R., Ratner, S., and Rittenberg, D., Behaviour of antibody protein toward dietary nitrogen in active and passive immunity. J. Biol. Chem., 1942, 144, 555.
13. Technics of serodiagnostic tests for syphilis. Venereal Disease Education Institute, Raleigh, North Carolina, 1944.

14. Harris, A., Rosenberg, A: A., and Riedel, L. M., A microflocculation test for syphilis using cardiolipin antigen; preliminary report. J. Ven. Dis. Inform., 1946, 27, 169.

15. Alexander, L. J., and Schoch, A. G., Results of treatment of over a hundred contacts of early syphilis with a "One day abortive cure." Proceedings of the Symposium on Recent Advances in the Study of Venereal Diseases held April 9, 1948. To be published under the auspices of the Syphilis Study Section, National Institute of Health, U. S. Public Health Service.

16. Gregersen, M., A practical method for the determination of blood volume with the Dye T-1824. A survey of the present basis of the Dye method and its clinical applications. J. Lab. \& Clin. Med., 1944, 29, 1266. 